UDC 165.0; 37.01:001.8

DOI: $10.23951 / 2782-2575-2021-1-5-20$

\title{
AGAINST EPISTEMOLOGICAL HIERARCHIES: ON THE VALUE OF FORMING BODILY KNOWLEDGE*
}

\section{I.E. Sirotkina} Institute for the History of Natural Science and Technology Russian Academy of Science,
Russian Federation

The article reveals such concepts as "metis," "body techniques," "practical skill," "kinesthetic intelligence," and "movement skill." These concepts are united by the fact that the accumulation of knowledge is presented as a largely unconscious process in which muscles play the same role as the brain. The essence of these concepts can be expressed in the term "bodily knowledge," which contrasts itself in the epistemological sense with codified practical knowledge, instructions, and rules - techne. Bodily knowledge is based on movements and muscle sensations. Russian physiologist I.M. Sechenov called this sensation "dark," pointing out that such sensations are almost impossible to comprehend, describe, and analyze. However, such feelings cannot be entirely opposed to thought. This "smart skill," as poet and writer Varlam Shalamov called it, can be considered a separate type of cognition. This article is an attempt to comprehensively discuss the concept of "body knowledge."

Keywords: metis, techne, skill, movement skill, kinesthetic intelligence, body techniques.

There is a citation from the poem "Memory" by Varlam Shalamov in the title of this paper:

\author{
Если ты владел умело \\ Топором или пилой, \\ Остается в мышцах тела \\ Память радости былой. \\ То, что некогда зубрила \\ Осторожная рука, \\ Удержавшая зубило \\ Под ударом молотка. \\ Вновь почти без напряженья \\ Обретает каждый раз \\ Равновесие движенья \\ Без распоряженья глаз.
Эти навыки труда
В нашем теле, без сомненья, \\ Это умное уменье, \\ Затаились навсегда
}

If you ever have mastered

An ax or a saw,

The memory of the old days' joy

Remains in the muscles of your body.

What once was memorized

By a careful hand

Holding a chisel

Under the blow of the hammer.

\author{
Now once again \\ Restores its balance \\ Almost without tension \\ And without looking \\ This smart skill, \\ These labor habits \\ Are without a doubt, \\ Hidden forever in our body.
}

(Approx. prose translation)

$1957[1]$

Growing up in the small town of Vologda, where even now central heating is not available
erywhere, Shalamov knew how to work with an ax and a saw from a very young age. This skill

* Original Russian language version of the article: Sirotkina I.E. "Umnoye umeniye": v kakom smysle mozhno govorit' o "telesnom znanii"? ["Sage Skill":in what Sense Can one Speak of"Bodily Knowledge"?]._Praksema. Problemy vizual'noj semiotiki - ПPA三HMA. Journal of Visual Semiotics, 2020, no. 2 (24), pp. 225-250. 
came in handy when he was forced to move to the Siberian sawmills and mines. Without the bodily knowledge of labor skills, without the "smart skill," he would most likely not have survived in the Gulag. In any case, the fifty-year-old poet believed that the body memory is stronger than the brain memory because the latter can forget what has been learned:

\author{
Сколько в жизни нашей смыто \\ Мощною рекой времен \\ Разноцветных пятен быта, \\ Добрых дел и злых имен. \\ Мозг не помнит, мозг не может, \\ Не старается сберечь \\ То, что знают мышцы, кожа, \\ Память пальцев, память плеч.
}

\author{
How much in our life - \\ Good deeds and evil names - \\ Is washed away \\ By the mighty river of times \\ The brain does not remember, \\ The brain cannot save, \\ What do muscles and skin know: \\ The memory of fingers and shoulders.
}

How can we describe this body memory, this "muscular knowledge" - not in poetic language, but in more or less academic prose? Several synonymous concept words are used for that purpose: practical skill, skill, metis, body techniques, motor, or kinesthetic intelligence. They are in one group because the accumulation of knowledge is often presented as a non-verbal process, threequarters of which are unconscious, but the muscular feeling is also responsible to the same extent as consciousness or the brain. For example, a singer friend of mine, who sang in the choir for many years, decided to start a solo career in opera. She complained that she had to rebuild the entire muscular apparatus involved in singing, posture, and behavior on stage. In other words, the knowledge of how to be an opera soloist is muscular or physical.

Shalamov compares muscle memory with reading a poem by heart:

\author{
Эти точные движенья, \\ Позабытые давно, - \\ Как поток стихотворенья, \\ Что на память прочтено.
}

\author{
These precise movements \\ Forgotten long ago \\ Like the flow of a poem \\ Read by heart
}

\section{(Approx. prose translation)}

According to the poet, motor skills are "precise," "intelligent," and merge into a stream and then into the verse flow. However, physiologists have discussed the "unity" of the skill, the "kinetic melody" earlier, at the beginning of the twentieth century, but in a slightly different sense. For instance, in a book scheduled for publication in 1937 but which remained unpublished, the physiologist Nikolai Bernstein writes about "coordination 'melodies" [2, p. 251]. In the book, he characterizes the nervous system's flexibility, the ability to switch between skills, achieve the same result with the help of other organs, a different motor alignment. In the same "musical" way, mountain climbers describe their motor experience. Reinhold Messner, famous for the speed of his ascents (he had been climbing rocks in the Dolomites since childhood), mentioned "flow," "melody," and compared rock climbing with ballet [3, p. 345].

The idea of this article is partly inspired by the controversy between contemporary dance and ballet. From the moment of its birth at the beginning of the twentieth century, modern dance has opposed itself to ballet with its pointe technique, codified positions of hands and feet, 32 fouettés, and other accepted virtuosity signs. Modern dance supporters criticize ballet for its "virtuosity" and technique prevalence, not feelings and thoughts. Instead of ballet techniques, different avant- 
garde dancers and choreographers offered emotionality, expressiveness, and even conceptuality. A "non-dance" movement appeared, first in America and then in Europe; its authors opposed the well-trained bodies of classical dancers to the "ordinary" bodies of new dance artists. This is how "modern" dancers made it clear that ballet is just a routine, training, and exercise, saying that they are the real art [4].

Not only ballet but also breakdance or acrobatic rock and roll - require the highest technique complexity, lengthy training, and strict discipline. We saw an advertisement for dance courses that taught people how to interact with a partner (in club dances) without the partner's presence. However, the course authors emphasized that they count on "smart" students with high intelligence. But, can intelligence completely replace practical, bodily knowledge or muscle memory? This is the first issue that we would like to discuss. And the second one - is "technique" really the opposite of thinking, and do the skillful and disciplined moves exclude thought? Is the technique, the training, the "virtuosity" really "brainless"? Samuel Beckett's Rule No. 40 says: "Dance first, think later. It is the natural order". According to contemporary choreographers, "dance is one way of thinking" [5]. Let us try to examine a motor skill as a "smart skill," bodily knowledge.

\section{Motor skill and kinesthetic intelligence}

It is impossible to learn to swim in a dry pool, just as it is impossible to learn to ride a bicycle only theoretically. In practice, numerous trials and errors are essential; "learning from mistakes" is the core of such activities. "To develop intuition, - writes the philosopher and anthropologist James Scott, -you have to make at least one mistake and mess things up" [6, pp. 351-352]. No instruction will allow beginners to ride a bike on the first attempt - they will need to fall more than once to catch a sense of balance in motion. Alternatively, as the physiologist and researcher in the field of motor control and motor learning, Nikolai Bernstein writes:

"The student's legs begin to feel the correct circular shape of the feet's movements and the specific variable resistance made by the pedals. The hands master the agility of the steering fork and adapt to combine its arbitrary turns with leaning on it. It takes much longer to develop and gradually sharpen the sense of the side tilts of the bicycle and the feeling of how the steering wheel's turns affect them" [7, p. 217].

The biomechanical core of the formed skill consists of "moving the center of gravity under the support". New attempts and failures are needed to automate the skill. However, it is not a matter of "memorizing" at all. Repetition is necessary so that each time the student acquires almost imperceptible bodily adaptations. According to Bernstein, during the formation of a skill, repetition without repetition takes place. With each new attempt, a person receives new sensations that are not visible from the outside. Such sensations from the "periphery" of movement proprioceptors in the skin, muscles, tendons - Bernstein calls "sensory corrections" (later, with the advent of cybernetics, he started to use the term "feedback"). So, the periphery sends sensory signals to the center, which constantly "correct" the movement model depending on the situation developing on the periphery. This is how a person learns not to fall anymore:

"An old instinct, connected with previous experience in space, may at first cause a person to turn the steering wheel to the right when it tips to the left. Little by little, this instinct fades, and the novice independently or at the direction of the teacher responds to these tips to the left by turning the steering wheel to the left, since the general center of gravity moves under the bicycle's support points and restore the disturbed balance" [7, p. 217].

The nervous system performs a tremendous amount of work: "for this, it must practically familiarize itself, or, as they like to say now, work it out, - Bernstein adds with sinister irony, 
hinting at party 'purge' and 'elaboration,' a huge number of variants of the movement. The body must try it out in order to experience all the sensations that will make the basis of its sensory corrections" [7, p. 217].

Bernstein's view on the mechanism of skill formation was very different from the theory of I.P. Pavlov. The latter believed that in the course of the conditioned reflex closure (which he saw in a smooth increase in the dripping saliva amount), "the neural pathways are blazed." However, the skill automation is, instead, a sudden insight, "a flash," exclamation "aha!" The student suddenly realizes that the water is holding him/her or that the bike has acquired such stability as if it had grown a third wheel. At the moment of movement's automation, the outbreak of sensitivity, attention, and muscles is called "relaxation." "The rigid bridle of sensory corrections that were necessary before to prevent movement from derailing" is now relaxed [7, pp. 233-234].

Even if it has become an automatism, a skill is a smart move. Bernstein does not equate motor skill to a stimulus-response but views it as the solution of a motor problem, an intellectual act. He did not use the word "intelligence," preferring its motor equivalent, "dexterity" (see below). However, his followers use such terms as "bodily-motor" or "kinesthetic intelligence." Psychologist A.V. Zaporozhets was among the first to use this term. He wrote: "there are not only motor perception and memory, but also motor intelligence, which has not been carefully studied" [8, p. 163]. His American colleague Howard Gardner proposed a theory of multiple intelligences, including bodily-kinesthetic intelligence. Referring to Bernstein, Gardner writes that this kind of intelligence is "the ability to control one's movements and handle objects skillfully" [9, p. 208; 10]. Kinesthetic intelligence is inherent in humans and animals, capable of learning and forming motor skills.

The term "motor intelligence" has some predecessors. In the Interwar period, the term "wisdom of the body" appeared in the titles of scientific works: in 1932, a book by the physiologist Walter Cannon was published under this title [11] $]^{1}$, and five years later, the movement's practitioner Mabel Elsworth Todd published the book "The Thinking Body" - about developing of refined neuromuscular coordination with the help of mental images and conscious relaxation [12]. At the same time, in Soviet Russia, poet Osip Mandelstam wrote about the "thinking body" [13].

After the Second World War, it became clear to many that it was necessary to change the political system foundations, starting with education. In the updated education ideology, such qualities as openness, awareness, reflection, creativity, and freedom were recognized as valuable - as opposed to control, discipline, and authoritarianism. Attention to the body, the development of a sense of movement, and awareness of the inner state have become the goals of new physical and motor education systems. They replaced training systems based on obedience, discipline, and conformity. According to the historian of physical culture Georges Vigarello, in the physical training programs that have appeared after the war, the central role was given to the inner side of the movement, the feeling of one's own body [14, pp. 177-178]. The new approach offered an in-depth self-study, conscious perception of one's own body and movements, the use of imagination and visualization of different parts of the body and its dynamics, and the formation of a holistic body image.

The desire to develop and improve motor skills has led to the emergence of an entire industry of body-movement practices. Over the decades that have passed since then, the old group of physical education specialists - sports coaches, rehabilitation doctors, physical education instructors, and dance teachers - have been joined by the followers of new systems: the Alexander

\footnotetext{
${ }^{1}$ However, under the "wisdom of the body," Walter Cannon understood the ability of the body to maintain a balanced state - homeostasis. Bernstein, on the other hand, did not agree with this, believing that the goal of the body is activity.
} 
technique, the Feldenkrais Method, Hanna Somatics, Lulu Sweigard's ideokinesis, The Body Mind Approach, and others. Many of them are based on feeling or awareness of movement, bodily knowledge, and kinesthetic intelligence. Cognitive psychology has also changed: it includes such concepts as "embodiment," "embodied mind" (i.e., mind in the flesh), "situated cognition" (cognition adapted to circumstances), and "extended cognition" [15-17]. Today, sociologists (following Pierre Bourdieu and his concept of "habitus") have concluded that "fleshly understanding and sentient comprehension" may and should be used to help the analytical tools of the mind. In particular, an anthropologist or a sociologist who studies something by participant observation must take into account bodily knowledge [18, p. 9]. A follower of Bourdieu, sociologist, and boxer Loïc Wacquant states that our "social competence," i.e., practical knowledge and skills, is based on "visceral know-how and pre-discursive skills," and in this, we all resemble martial artists ("we are all martial artists of one sort or another") [18, p. 12].

Although the terminology and details may differ, these areas are united by a common idea: our knowledge of the world is not transcendent; it is not beyond this world; it is rooted in our body and its practices, including the movement practices, interaction with other people, and manipulation of things.

\section{Metis or Cunning Odysseus}

For almost three millennia, Odysseus has been considered as the standard of worldly wisdom, practical intelligence. Homer calls him "cunning" not only because he tricked Circe, the cyclops Polyphemus, and gave the order to tie himself to the ship's mast to avoid the Sirens' temptation but also because he constantly restored the crew and the ship. Thanks to his experience, practical knowledge, and flexible tactics, Odysseus outsmarts his enemies and returns home. "Cunning," "agility," "resourcefulness," and "dexterity" are not divided between the body and mind of the hero but characterize the person as a whole. The ancient Greeks called it "metis" [19]. Metis was the name of the first bride of Zeus, who deceived his father, Chronos. She gave Chronos a herb that made him vomit up Zeus's older brothers (Chronos consumed them, fearing that they would turn against him). Zeus, in turn, ate Mestizo, thus appropriating all her intelligence and cunning before she could give birth to Athena. Athena was born from the thigh of Zeus.

Usually, "metis" is translated as "cunning." In a broad sense, this word means a wide variety of practical skills and acquired information in a strong connection with the constantly changing natural and human environment. Sociologist James Scott prefers the term "metis" to expressions such as "local knowledge" or "folk wisdom" because they limit such knowledge to "traditional" cultures [6, p. 353]. Metis, on the other hand, exists in the most modern actions, takes place everywhere: from a factory to a research laboratory. In addition, "local knowledge" is too static to reflect the dynamic aspect of metis associated with constant change. Metis is a quick and appropriate reaction to unpredictable events, whether it be a change in the weather or sudden movements of the enemy.

"Metis" can be translated as "dexterity" or "agility." Although "dexterity" is not a scientific concept but an everyday one, it entered the academic vocabulary thanks to the doctors and the creators of sports and physical education systems. In Russia, at the end of the 19th century, Peter Franzevich Lesgaft, an anatomy teacher who founded the first courses for training female physical education trainers, wrote about the development of dexterity. In the gymnastic systems at that time, the emphasis was made on strength and endurance. Lesgaft, on the other hand, believed that physical exercise is designed to educate not only the body but also the mind of the child. Criticizing the existing gymnastics for being mechanical, he suggested that instead, the training should be held within the course of "natural" exercises and games. The child should "learn to 
consciously perform the most physical work with the least effort in the shortest time possible, and to act gracefully and energetically" [20, p. 239]. At first, the child is only required to perform simple motor skills correctly: walking, running, jumping, throwing. The following skills should be improved at the next stage: running as fast as possible, jumping as high as possible. Finally, in the third stage, a person learns to consciously control his/her movements, calculate them in time and space, and perform them with maximum accuracy - for example, to run a certain distance at a precisely specified time. So this is what dexterity exactly means.

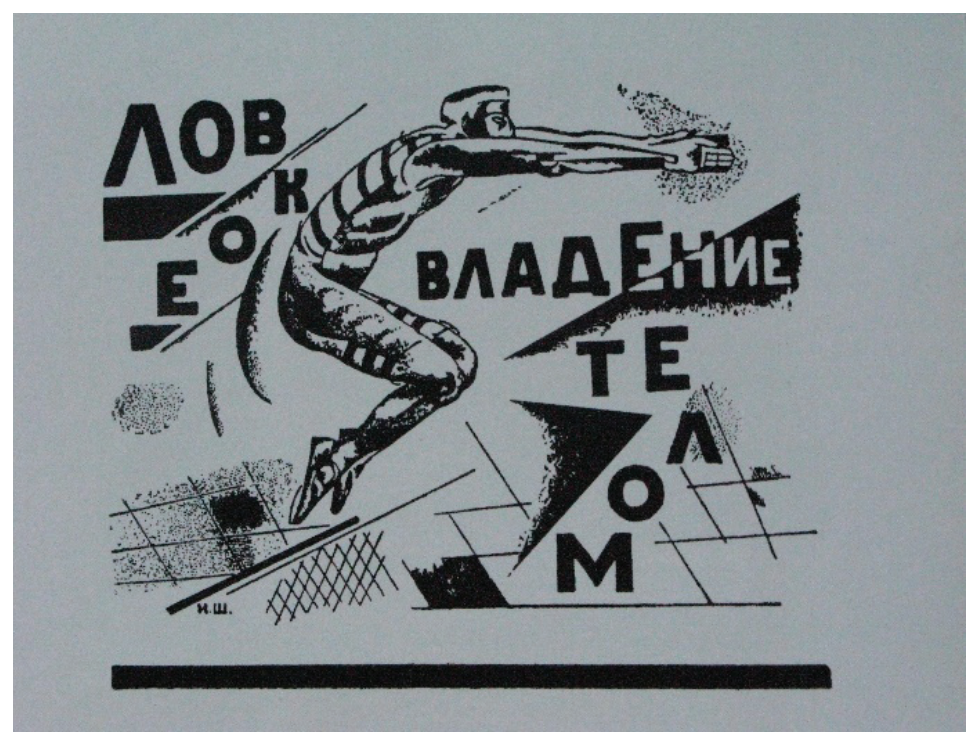

Fig. 1. Ilya Shlepyanov. "Dexterous Body Control", the early 1920s.

The scientist of the next generation after Lesgaft, Nikolai Bernstein, devoted an entire book to dexterity, where he also defines dexterity as an effective solution to a motor problem:

Dexterity is the ability to move out of any position, i.e., the ability to cope with any motor task that has arisen:

1) correctly (i.e., adequately and accurately),

2) quickly (i.e., quickly and efficiently),

3) rationally (i.e., rational and economical) and

4) inventively (i.e., flexible and proactive) [7, p. 267].

However, unlike Lesgaft, he does not include beauty or consciousness in the definition of dexterity. A rational (i.e., reasonable and economical) solution to a motor problem - for example, the movement of a football player's foot, scoring a ball from an uncomfortable position - occurs at lightning speed, without the consciousness participation. Here is how a football player is ready to hit the ball but slips and falls:

"His right foot went too far to the right, and the ball rolled to the left. Before the player had time to realize anything consciously, his instinct and experience were already implementing a new solution to the same problem: the balance after tripping was transferred to his right leg, giving him a direct blow that neither his teammates nor the opponent's goalkeeper, who was not prepared for a shot from there, could have foreseen. The goal was scored. The whole scene took hardly more than two seconds" [7, p. 266].

Bernstein calls "antecipation" such a mechanical, unconscious ability to foresee (insisting that this term should be written with an "e" since in Latin, "ante" means "before"). The movement 
simultaneously begins with the event that triggers the movement, or even before it. Lightning-fast and anticipatory reactions are extremely important in hand-to-hand combat, airplane combat, fencing, or boxing. Football, boxing, wrestling, and fencing require an instant automatic reaction to the opponent's attacks. A dexterous "cunning" player or fighter knows how to perform a movement in such a way as to provoke a retaliatory strike, which then is used for one's own purposes. Bernstein quotes the hygienist F. Lagrange:

"The old swordsman had fought so many opponents that he had reached the point of accurately classifying different manners and different temperaments. After one or two "false attacks," he already knows the strength and the style of the opponent. He guesses his intentions using "probability calculus" of some sort that is almost equivalent to certainty. Each day can bring him a new experience, as each new opponent is a case for a new study. All masters suggest changing opponents frequently in order to become proficient in fencing. When you have reached a certain strength, you no longer progress if you always fight the same opponent, even if you are a good master" [7, pp. 263-264].

The philosopher Ludwig Wittgenstein considered the ability to anticipate, foresee, imagine the future more important than the ability to predict: "one cannot predict what cannot be anticipated, just as one cannot anticipate what can be predicted" (quoted from [21, p. 71]). Researchers in the XIXth century wrote a lot about anticipation as a relatively unconscious foresight. However, starting with Sigmund Freud, the unconscious has been associated not with the future but with the past. Unlike many of his colleagues (and, above all, I.P. Pavlov), Bernstein was interested in the action determinants related not only to the past but rather to the future. Physiologist Alain Bertoz, who considers himself a student of Bernstein, notes that his teacher was one of the first to make "anticipation," "anticipatory reflection," a constructive element of movement [21, p. 88].

"Antecipation," instant anticipatory reactions are essential not only in the fight. In 2015, we interviewed a well-known test pilot and cosmonaut, Igor Petrovich Volk (1937-2017). He had been flying for almost half a century, and most of that time, he had been testing new equipment. How did he manage to complete tasks successfully and survive in a profession where people do not live long? In response to our question, Igor Petrovich said that he could feel, anticipate the onset of an emergency, and immediately react to prevent this situation. This ability comes with experience: the more significant the accumulated experience, the higher the possibility to feel in advance the approach of the external event to which you need to respond. According to Volk, he knew the technique "in his gut," felt it with his body: "is it possible to hug a woman and not feel her?" - he explained to me jokingly. This bodily "cunning" or metis, Volk developed by experience, having spent 7000 hours at the yoke, more than half of which were spent in test flights, mastering new aircraft.

If metis, dexterity, or bodily knowledge are acquired through practice, how do they relate to another kind of practical knowledge: techne, a formalized and codified knowledge.

\section{Techne and body techniques}

Sociologist and anthropologist Marcel Mauss viewed "body techniques" as culturally-specific ways to stand, sit, cook, sleep, wash, and express emotions [22]. As an example, Mauss refers to swimming. He and his contemporaries swam breaststroke with one feature - on the inhale, they sucked water and then, on the exhale, spat it out (one of the swimmers joked that Mauss looked like a paddle steamer). Later, the crawl style became widespread, but Mauss admits that he could never switch to it: the style of swimming he mastered as a child entered his body, became part of 
him. It was due to the breathing technique peculiar to this style - after all, the way we breathe is complicated to control [23] $]^{1}$.

Just like metis, body techniques are part of personal experience, or, in the words of Michael Polanyi, "tacit knowledge" [24]. These techniques are embodied as a part of everyday life. On the contrary, general, abstract practical knowledge is denoted by the term "techne." James Scott says that this kind of knowledge was utterly different for the Greek philosophers, especially for Plato $[6$, p. 370]. Body techniques may not be recognized, rarely verbalized, and even less often codified.

In contrast, general pragmatic-technical knowledge, or techne, can be accurately and exhaustively expressed in the form of strict and rigorous rules, principles, and conclusions. We heard an example of techne from a friend whose grandmother was an agronomist. One day when she was visiting her friends, she saw cucumber seedlings on the windowsill and said to the owners (according to her, entirely automatically): "Your seedlings are not viable. They grew without light too long and got pale. Throw it away and soak the new seeds." This technical knowledge was verbalized and codified, and she inherited it from her grandmother since she has never been engaged in gardening.

While metis is associated with personal skill and the ability to "feel" with practical results, techne is characterized by impersonal, often quantitative accuracy and requires explanation, verification, validation. Metis is contextual and specific, while techne is universal. Finally, techne is most suitable for those activities with a single primary goal, and this goal can be separated from the activity itself and can be measured quantitatively. Therefore, techne is used in management, including state management. However, metis also has its advantages: it is indispensable when quick reaction, improvisation, and skillful successive approaches to the problem's solution are required. Metis enters the game when it is essential to make a prediction based on insufficient grounds - for example, to assess early signs of how well or bad things are going. It is essential in situations that are "temporary, changeable, ambiguous, and confusing; situations that do not lend themselves to accurate assessment, rigorous analysis, and solid logic." In these situations, the epistemic alternative to metis performs "much slower and painstaking, requires more intensive investment, and is not always convincing" [6, p. 362]. Scott writes that "if your life depended on a ship navigating in bad weather, you would prefer a captain with much experience instead of, say, a brilliant physicist who can analyze the laws of navigation but has never steered a ship" [6, p. 362].

The distinction between techne and body techniques is at the heart of the work-to-rule strike (the French call it "grève du zele," "the strike of diligence"). During such a strike, employees strictly observe the rules and instructions and perform only those specified in the contract. As a result, the work is slowed down considerably and may even stop altogether. The work-to-rule strike shows that working with full compliance with the rules is less productive than taking the initiative and that the current production is very much dependent on informal arrangements and improvisations [6, p. 348]. Another example of how difficult it is to perform a movement or an action based solely on instructions is an attempt to reconstruct the exercises of "musical movement," 2 made in the Studio-Laboratory of musical movement "Terpsichore" (where the author of this article also studies). Some of the exercises created a century ago are almost lost:

\footnotetext{
${ }^{1}$ Perhaps Mauss did not master the crawl because he had a "water sense" in the breaststroke, and he was never able to acquire it in the crawl. The "feeling of water," which is well known to good swimmers and athletes, consists in the ability to "lean" on the water and "push off" from it. According to experienced coaches, this feeling is the result of long training sessions, but it came not while working on the style but after spending quite a time passing long and medium distance [23]. Perhaps Mauss simply did not have time to use the crawl as much as he had previously used the breaststroke in his life, and when crawling, he did not have a "sense of water."

${ }^{2}$ Musical movement is a national tradition of a free dance, which is more than a hundred years old, see www.dancefrommusic.ru
} 
only the descriptions and music to which these exercises are performed have been preserved. To demonstrate to the reader how difficult it is to understand the movement from the instructions, we will describe the exercise "Step sighs" (performed to the music from the opera "Pebbles" by the composer Monyushko). Here is the description:

Bars 2-6. On each beat - inhale on one, two, three, and make a quick exhale on four. At the same time, the upper breath takes three short breaths without exhalations; the rib cage rises a "step" higher each time. On four - a complete active exhalation, the chest is lowered.

Bars 7-9. Short upper breaths accompany the main breath only on one and two of the 7th bar; then, they merge with it in a full deep breath on the <illegible $>$. On one and three of the 8th bar and one of the 9th bar, a complete exhalation occurs in three steps, which continues until the end of the musical phrase. Further (on 11-12 and 13-14 bars.), the main breaths last for two bars and are accompanied by short upper breaths for each count, end with general exhalations, etc. ${ }^{1}$

Fortunately, the musical movement is a practical living tradition, transmitted, however, not "by word of mouth" or "from hand to hand," but (as in general in choreography) - "from foot to foot."

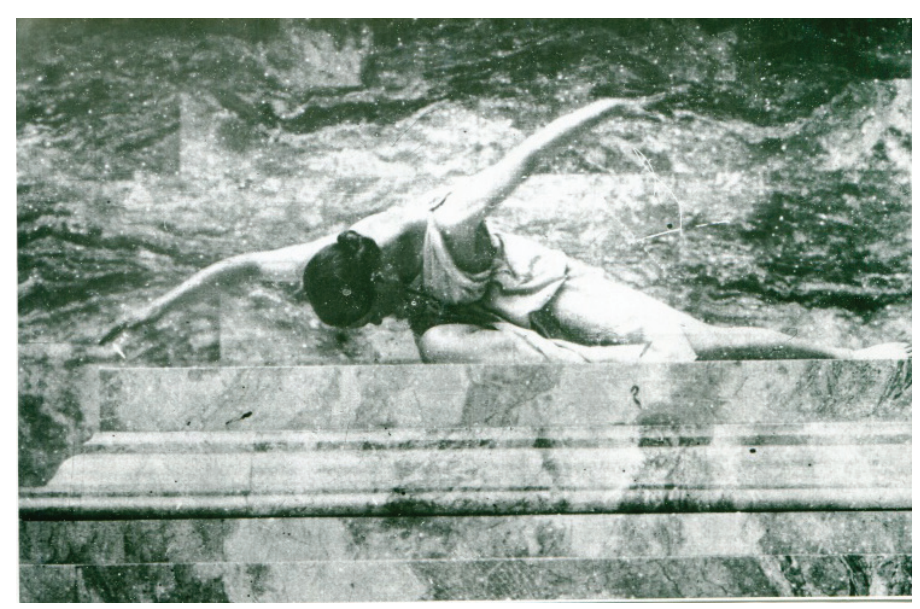

Fig. 2. Stephanida Rudneva. Musical and choreographic etude "Wings," the early 1920s.

There is a triumph of metis in such situations. So why does the academic world reject bodily skill in favor of more abstract, codified knowledge? Perhaps it is because "discoveries" of metis are practical, contextual, and time-bound, and scientific reasoning, on the other hand, is based on generalized solutions [6, p. 363]. Paradoxically, the low status of metis in the academic world contributes to its strengths in practical life. Doesn't this tell us something about academic knowledge itself? The actual practice of science is something entirely different - in the philosophical literature, it is usually placed in the context of discovery, as opposed to the context of justification $[25$, p. $5 ; 26 ; 27]$. Ethnomethodologists emphasize the difference between de facto practice in the laboratory, on the one hand, and the codified form of knowledge presented in articles or communications, on the other [28-30]. If proof of a mathematical law must follow the principles of techne, then its discovery requires personal knowledge or metis. The contexts (conditions of possibility) of discovery are so complex and unique that formal procedures for making decisions and drawing rational conclusions become impossible.

James Scott presented his analysis of metis to answer the question (stated in the title of his book), "How Certain Schemes to Improve the Human Condition Have Failed." Why did the most beautiful utopias, the most coherent plans for improving life, almost always end in nothing at best

\footnotetext{
${ }^{1}$ Compiled by one of the founders of the method of musical movement, S.D. Rudneva, see www.dancefrommusic.ru
} 
and at worst - in a catastrophe for humanity? Why are authoritarian, high-modern systems so potentially destructive? The answer that Scott suggests: because such systems ignore, often to the point of complete suppression, the practical skills, and without such skills, complex activities are unthinkable. "Many forms of high modernism have replaced the valuable collaboration between these two sides of knowledge with an 'imperial' view of science that rejects practical skill as insignificant at best and ignorant at worst" [6, p. 349]. The dispute between scientific and practical knowledge over priority reflects the political struggle for the hegemony between specialists and their departments.

Scott illustrates this with cases of Taylorism and agricultural rationalization. By "scientific management," Taylor meant "collecting all the traditional knowledge that workers had in the past, and then classifying and reducing this knowledge to rules, laws, formulas" [6, p. 349]. In the new system, all the technological developments that the workers had back in the old system should be examined by the management structure following scientific laws. Taylorism is a system where the mind is in complete control of the body. In a Taylorist factory, only the manager has access to the knowledge and control of the entire process, and the role of the worker is reduced to performing small, often minute general production operations. The goal of Taylor - who, according to Scott, was a genius of modern methods of mass production - was the destruction of metis and transformation of the resisting supposedly independent craftsmen population into more suitable units or "working hands" [6, p. 349].

At least briefly, let us turn to the history of labor rationalization in the early USSR and see how the hierarchy of knowledge, in which practical knowledge is subordinated to theoretical knowledge, and body to mind, is maintained by a specific social order. And not only by capitalists but also by socialists.

\section{Skill and mind}

In the poem "Memory" quoted above, Varlam Shalamov mentions a hammer and chisel and, I think, does so on purpose.

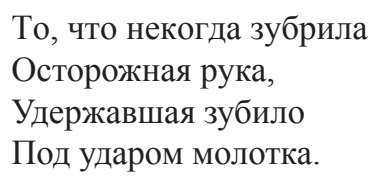

What once was memorized

By a careful hand

Holding a chisel

Under the blow of the hammer.

(Approx. prose translation)

Hitting a chisel with a hammer became a training activity, implemented in the early 1920s by Alexey Kapitonovich Gastev (1882-1939), who practiced the Scientific Organization of Labor (SOL). In the Central Institute of Labor (CIL), which he created, hundreds of yesterday's peasants, future workers, were trained to work on metal with the help of special simulators: how to hold a hammer, and swing and hit the chisel... Shalamov was living in Moscow at the time and no doubt had heard of Gastev and his system of rationalizing labor. Let us not forget that Gastev was already a recognized poet whose collections (including the "Poetry of the Workers' Strike") had already been published in several editions, and Shalamov was just a beginner.

SOL has been compared to Taylorism, but Gastev refused to have anything to do with Taylor's "sweatshop capitalist system." Of course, Gastev also wanted to organize the scientific work rationally and sought for the greatest efficiency at the lowest cost: "A skillful organizer can turn things around in straitened circumstances: in limited time, in a minimal space, with a small number of tools and with limited material" [30]. However, Gastev objected to the absolute separation of management and execution between people - perhaps he thought so for ideological 
reasons and not for efficiency reasons. The Soviet cult of labor endowed the proletariat with all possible virtues, including "consciousness," intelligence, and status higher than the intelligentsia status. Therefore, Gastev called the worker "manager" or "director" of the machine and did not separate the operation's execution from its planning. Firstly, the worker needs to plan everything out, present a "working draft" and the image of the part to be manufactured so that "a real technical bureau works in a person's head" [31]

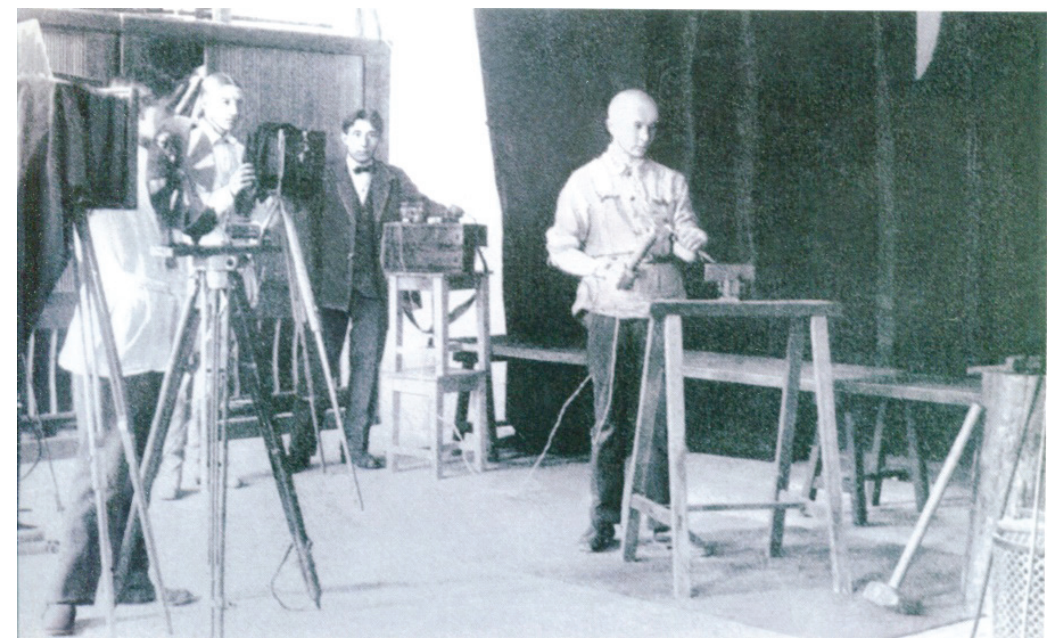

Fig. 3. Loop-shooting of labor movements (hammer blow on chisel) in the Central Institute of Labor laboratory, the mid-1920s.

Gastev defined "motor culture" as "the sum of the people's motor habits and skills"; it is "the movement of one's own body, expressed in such acts as protecting the body from attack, the attack itself, the pursuit, motor power, speed, what is called motor speed, the precision of movements" [31]. To work "culturally" meant "to work smoothly, to work in order, to work cleanly" [32, p. 27]. At the same time, he believed that only a state could create a new culture, as well as a new economy: "never before has the social and economic role of the state been so great as in our days. Therefore, our culture must at the same time be a state culture" [32, p. 27]. In the Proletkult, Gastev was perhaps the greatest etatist. He wanted factories across the country to become "giant laboratories" where the machine organizes the workers' actions and cultivates selfcontrol, discipline, and intelligence. Gastev opposed the new motor culture to the "frozen modern intellectual culture" - the sedentary existence of the intelligentsia, including armchair scientists and "pen workers." In this, one can see anti-intellectualism or criticism of the gap between the mind and the body. "A dexterous and well-aimed blow, sudden, interrupted, subtle, calculated pressure, dexterous transfer, and lifting of weights - he wrote - all this should be valued just as the higher intellectual activity of our brain" [32, p. 17].

Despite the attempt to distance itself from Taylorism, the Soviet SOL possessed all its features: the breakdown of the labor process into operations, the standardization of each of them, strict timekeeping, the worker training for labor operations "from scratch," the creation of new "labor sets." One may wonder what Gastev did not like, for example, in the village blacksmith's labor movements? After all, a blacksmith's blow with a hammer on an anvil is similar to smashing a chisel with a hammer, one of the first labor movements, which was rationalized by the CIL. The village blacksmith is a handicraftsman who works alone or with an assistant, who takes over the

${ }^{1}$ The memo "How to work" compiled by Gastev had a subtitle: "How to invent." Here one can recognize "The Juvenile Sea " by Andrey Platonov - his hero, the engineer Vermo, is very similar to the visionary Gastev. "Why do we need work at all as a repetition of monotonous processes; we need to replace it with a continuous creativity of inventions!" - reflects Vermo "in the silence of a large space"; see: [33, 188]. 
craft from his father or mentor, and who has unique techniques and individually manages time and energy. Village handicraftsmen possess not just work experience but also a powerful rural way of life and the self-consciousness of a person rooted in tradition. Unlike the peasant and the craftsman, the factory worker receives strength not from tradition but from the organization and the crowd. In order to do this, work operations need to be unified, subordinated to one standard, removed from the individuality that manifests itself in the body: the handwriting, gait, and other movements of each person that are individual. However, a crowd where everyone acts in the same way and the same rhythm can be a source of an almost supernatural force that can frighten or inspire ${ }^{1}$.

The "zeroing" of past labor experience, including peasant experience, is similar to how the avant-gardists, including Kazimir Malevich, "zeroed" the old art. Gastev considered the peasantry "a solid untouched virgin land" and agitated for "going to the countryside as revolutionary colonialists":

Setting up a blacksmith shop, setting up the inventory repair, setting tools, iron fastenings in wooden equipment, planning a vegetable garden, and thousands of small but demonstrative cases - this is the installation program. Even more evidential and instructive for the peasant will be bringing

\section{CULTURE TO VIRGIN LANDS}

to empty, abandoned, or stray places [31].

In the empty, tabula rasa-like bodies of the peasants, the educator of the proletariat had to write their signs ${ }^{2}$.

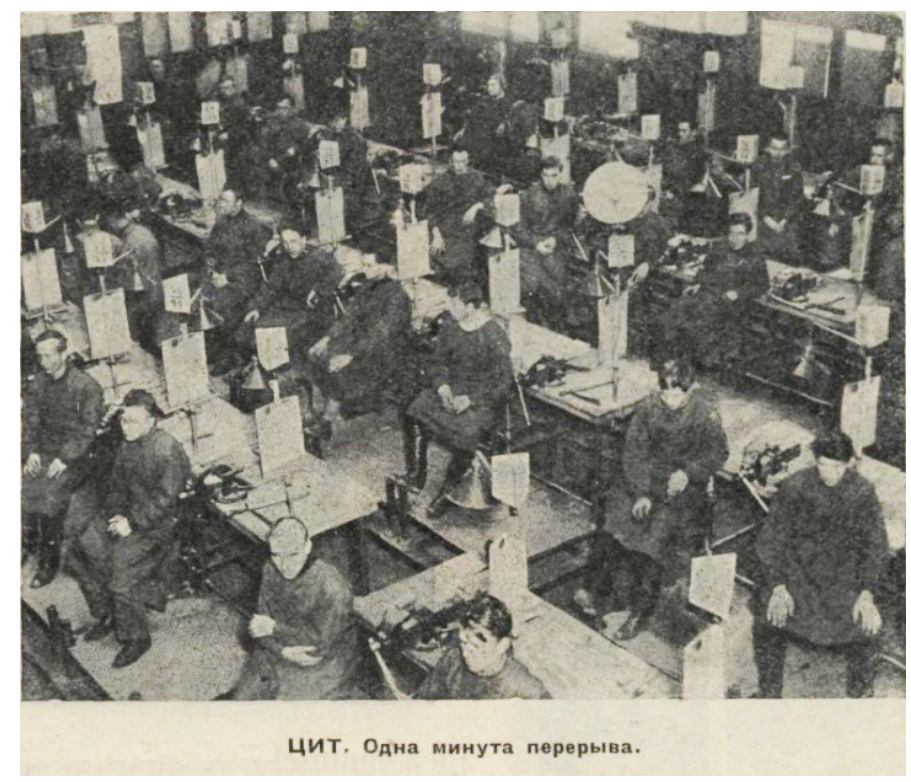

Fig. 4. Metalwork training in the workshops of the CIL, the mid-1920s.

\footnotetext{
${ }^{1}$ Siegfried Kracauer was one of the first who wrote about this. According to him, In the army, at sports, at a factory, the bodies of people are formed into an "ornament of the masses": "Not the people but the figures formed by them which are not woven out of thin air, but grow out of the community. <...> As for those who have broken away from the collective and think of themselves as individuals with an independent spirit, such people will find their inconsistency in the formation of new configurations" [34, p. 42]. Many pictures made in The Central Institute of Labour give the impression of theatrical mise-en-scenes, even rows of workers are hitting the chisel with hammers in the same way.

${ }^{2}$ Long ago, I was sent to review the master's thesis by Simon Werrett, now a renowned historian of science. It was called eloquently: "Peasants are NOT working" [35]. The pun is that in English, "NOT" means "no" and in Russian, "HOT" sounds like an abbreviation of "Scientific Organization of Labor" ("Научная организация труда"). The title suggests that in industrial production, peasant labor is devalued, not considered as work. This, of course, is the general attitude of the modernizer towards a tradition that is subject to either complete abolition or drastic change.
} 
It would be a mistake to assume, Scott writes, that the destruction of metis is an unintended and unavoidable by-product of economic progress. The typical structure of handicraft production, he believes, could be efficient but almost always became a hindrance to capitalist profits. "The destruction of metis and its replacement with standardized formulas, legalized from above, is part of the agenda of both the state and large-scale bureaucratic capitalism" [6, pp. 376-377]. Gastev acted in a different political system, but the hierarchy of knowledge remained the same: codified and formalized knowledge was considered the main, while physical, practical knowledge was devalued and denied. In socialism, the system of handicraft production was also sacrificed to bureaucratic control over mass production (state-controlled production, alas, did not become effective). Under both regimes, the destruction of metis led to the replacement of local and personal knowledge with abstract, generalized knowledge, which is easier to centralize and use in bureaucratic classifications. Speaking about the human subject transformation into the subject of the human sciences, Michel Foucault connects the emergence of human science and society (including statistics, demography, biomedicine) with the centralized state formation and the control bureaucratization over subjects [36]. In such states, no matter what system they adhere to, rationalized, formal knowledge is valued much higher than practical knowledge and takes the central place in the hierarchy of types of knowledge. Perhaps this social order can be called "modernism."

\section{The value of bodily knowledge}

The disappearance of metis is not always regrettable. "The ability to wash clothes with a washboard or on the river's rock requires an undoubted skill, but it is happily forgotten by those who can afford to buy a washing machine, Scott writes. Similarly, darning skills were forgotten when cheap machine-knitted socks appeared on the market" [6, p. 376]. Liberation from hard work and drudgery does not lead to a complete loss of practical knowledge, since "no form of production or social life can be put into action by formulas alone, i.e., without metis." Scott believes that personal and local knowledge, "given its dispersion and relative independence, allows everything but regulation." Taylor's utopia - a factory in which the movements of each pair of hands would be reduced to automatism, like programmed devices, turned out to be unrealizable. Gastev's socialist utopia also did not come true ${ }^{1}$.

However, metis does not lose its position so quickly, especially in traditional activities such as agriculture. Here, there are many obstacles to "rationalization" and standardization - including criticism of standardized farm products from consumers. As noted by the anthropologist S.B. Adonyeva and her colleagues, in the village, metis is tied to the geographical location and a person's position in the social hierarchy:

"[metis] is deeply rooted in the local natural and social landscape, finely tuned to local meteorological conditions (river flooding and the formation of winter roads, the time of fishing and hunting). The practices based on it are consistent with other social cyclical processes, such as seasonal visits to the countryside by urban adult children, conscription, summer holidays, and commemorations. Everyday experience is also consistent with social hierarchies: time and circumstances caused by the change in the socio-economic system lead to restoration of the seniority hierarchy [38, p. 38].

They attribute this to the "metis paradox": Metis is not distributed democratically. On the one hand, everyone has a body, and therefore direct access to bodily knowledge. On the other hand, [37].

${ }^{1}$ However, just partially - because, according to figures provided by the $\mathrm{CIL}$, it managed to train half a million workers for the metal industry 
dexterity, agility, and perceptual abilities are not the same for different people. The acquisition of metis requires experience and practice, and it is also a factor of inequality. Finally, metis requires submission and self-discipline, i.e., adherence to the social hierarchy (which can resist democracy) [38, p. 39]. However, in the integration of metis in general practices, lifestyle, body, and social fabric, one can also see the key to resisting the power and dominant discourse. "Metis, stored by the memory of bodies and practices, is destroyed when bodies and practices are destroyed. If the bodies are still intact and the practices exist, then metis can be restored" [38, pp. 35-36].

The philosopher Judith Butler states that because we learn "body techniques" from other people, from their images and words, these techniques are always given to us through language and consciousness. Therefore, bodily experience provides endless possibilities for manipulating the individual by society [39]. On the contrary, Adonieva and her colleagues give metis a higher "noise immunity," i.e., invulnerability to external influences, primarily political ones, compared to discursive knowledge. Adonyeva believes that discursive knowledge is more vulnerable to the dominant discourse - it is easy to interpret it ideologically. In addition, it is possible to talk about direct, non-discursive knowledge. For example, traditionally, girls learned needlework "by the method of participatory observation," just watching how older women did it [38, p. 205]. The difference between discursive knowledge, transmitted through language and speech, and bodily knowledge, can also be explained in this way. The actual movement is performed with much greater body involvement and generates more intense and rich kinesthetic experiences than speech (which also includes movements) [40]. The process of learning new movements and still unfamiliar body techniques can play a crucial role here. Learning a skill always produces a unique experience - the movement itself, which is not limited to how it looks in the mirror or how it is described in words. In addition to the external side, every movement also has an inner side, facing the subject itself. Scott mentions an experiment conducted by the philosopher Charles Pierce:

"Pierce asked participants to lift two bodies and decide which one was heavier. At first, their assessment was rather raw. People had been doing this for a long time and eventually learned to identify minimal differences in weight. At the same time, they could not accurately describe their feelings, their sensations, but their actual ability to estimate weight increased enormously. Peirce saw these results as evidence of some subconscious connection between people through "weak interactions." For us, however, this experiment illustrates the rudimentary kind of knowledge that can only be acquired by practice, and the fact that it is almost impossible to transmit in written or oral form without direct practice" (cit. by: [6, p. 354]).

Maxine Sheets-Johnston, a former dancer and now a phenomenologist, a follower of Maurice Merleau-Ponty (whose work "Phenomenology of Perception" is among the most cited books on the importance of corporeity in cognition), also disagrees with the fact that metis always requires consciousness and verbalization [41]. She proves the importance of "muscle sense" in several thick volumes" - kinaesthesia and kinesthetic intelligence [42, p. 439]. The sense of movement, kinesthesia involved in the acquisition of the metis perfectly demonstrates that bodily knowledge is more than the product of discourse, verbal instructions. Moreover, as the skill is mastered in repeated movements, this discourse itself becomes kinesthetically conditioned.

The kinesthetic experience that movements and gestures produce is engaging because it can produce as yet unmarked and unrecognized sensations. In mastering new movements, gestures, skills, and abilities, a person creates new meanings, thereby proving one's own personal agency, activity. Can you remember being a child in the first grade when you first took a ballpoint or ink pen and learned to write with it? It was a completely incomprehensible kinesthetic experience, unmarked. At first, almost the whole body is involved in writing - sometimes, children write with 
their tongues out. Metis of writing did not come easily - some have a callus on our fingers for the rest of our lives. No less rich kinesthetic experience is accumulated when teaching writing in other cultures - for example, when teaching calligraphy, the art of hieroglyphics [43, p. 171]. As we learn and become adults, we tend to forget motor sensations, rich and essential kinesthetic experiences that the learning process generates. However, the bodily knowledge produced by this experience, fortunately, remains with us. If we keep this in mind, the consonances between "muscle" and "mind," "skill," and "spirit" will not seem so random.

\section{References}

1. Shalamov V. Collected works: In 4 volumes. Moscow: fiction VAGRIUS, 1998. URL: https://shalamov.ru/ library/9/7.html (accessed: 01/22/2020).

2. Bernstein N.A., Feigenberg I.M., Sirotkina I.E. (eds.) Modern searches in the physiology of the nervous process. Moscow: Smysl, 2003.

3. Smith R. The Sense of Movement: An Intellectual History. London: Process Press, 2019.

4. Banes S. Terpsichore in Sneakers: Post-modern Dance. Middletown, CT: Wesleyan University Press, 2011.

5. Gurskaya I. Dance story / based on the production of Wayne McGregor's "Autobiography". Topos. Literary and philosophical journal. 2019. URL: https:/www.topos.ru/article/proza/tancrasskaz-po-motivam-postanovkiavtobiografiya-ueyna-makgregora, published on-line 08/11/2019 (accessed: 22.01.2020).

6. Scott J. How Certain Schemes to Improve the Human Condition Have Failed. Translation from English by E.N. Gusinsky, Yu.I. Turchaninova. Moscow: University book, 2005.

7. Bernstein N.A., Feigenberg I.M. (ed.) On Dexterity and Its Development. Moscow: Physical culture and sport, 1991.

8. Zaporozhets A.V. Changing the motor skills of a preschooler child depending on the conditions and motives of his/ her activity. News of the Academy of Pedagogical Sciences of the Russian Soviet Federative Socialist Republic. Department of Psychology, 1948, issue 14, pp. 125-166.

9. Gardner H. Frames of Mind: The Theory of Multiple Intelligences. London: Heinemann, 1983.

10. Sirotkina I.E. The World as a Living Movement: An Intellectual Biography of Nikolai Bernstein. Moscow: Kogitocenter, 2018.

11. Cannon W.B. The Wisdom of the Body. New York: W.W. Norton, 1932.

12. Todd M.E. Study of the Dynamic Forces of Dynamic Man. Princeton, NJ: Princeton University Press, 1937.

13. Mandelstam O.E. “O. I ty, Moskva, sestra moya, legka...”. Poems, prose, memoirs, materials for biography. Moscow: Moscow worker, 1990.

14. Vigarello J. Train the body. In: Corbin A., Curtin J.-J., Vigarello J. (eds.) Body history. Volume 3. Change of view: XX century. Moscow: NLO, 2016.S. 149-184.

15. Johnson M. The Body in the Mind. The Bodily Basis of Meaning, Imagination, and Reasoning. The University of Chicago Press, 1987.

16. Clark A. Supersizing the Mind: Embodiment, Action, and Cognitive Extension. Oxford: Oxford University Press, 2008.

17. Gallagher S. Philosophical antecedents to situated cognition. In: Robbins P. and Aydede M. (Eds.). The Cambridge Handbook of Situated Cognition. Cambridge University Press, 2009. Pp. 35-51.

18. Wacquant L. Homines in Extremis: What Fighting Scholars Teach Us about Habitus. Body\&Society. 2013 , vol. 20(2), pp. 3-17.

19. Detienne M., Vernant J.-P. Cunning Intelligence in Greek Culture and Society. Trans. J. Lloyd. Atlantic Highlands, N.J.: Humanities Press, 1978, original: Les ruses d'intelligence: La metis des grecs. Paris: Flammarion, 1974.

20. Lesgaft P.F. Guidelines for the physical education of schoolchildren. Izbr. pedagogical op. Moscow: Pedagogika, 1988. S. 228-263.

21. Bertoz, A., Petit J.-L. The Physiology and Phenomenology of Action. Transl. by C. Macana. Oxford: Oxford University Pres2008s.

22. Mauss M. Body techniques. In: Societies, exchange, personality. Moscow: Science; Main edition of oriental literature, 1996. Pp. 242-263. 
23. Zhekulin S.A. The experience of psychological study of the formation of swimming skills in styles. In: Rudik P.A. (ed.) Psychomotorics and physical culture. Moscow: All-Russian Research Institute of Physical Culture and Sports, 1935. pp. 57-92.

24. Polanyi M. Personal Knowledge: Towards a Post-Critical Philosophy. Chicago: University of Chicago Press, 1958; Russian publication: Polanyi M. Personal knowledge. Moscow: Progress, 1985.

25. Bloor D. Knowledge and Social Imagery. Routledge, 1976.

26. Hoyningen-Huene P. Context of Discovery versus Context of Justification and Thomas Kuhn. In: Schickore J. and F. Steinle (eds.) Revisiting Discovery and Justification: Historical and Philosophical Perspectives on the Context Distinction. Springer, 2006. Pp. 119-132.

27. Kasavin I.T. Text. Discourse. Context. An introduction to the social epistemology of language. Moscow, 2008.

28. Latour B. Science in Action: How to Follow Scientists and Engineers through Society. Cambridge: Harvard University Press, 1987.

29. Hacking I. The Self-Vindication of the Laboratory Sciences. In: Pickering A. (ed.) Science as Practice and Culture. Chicago: University of Chicago Press, 1992. Pp. 29-64.

30. Pickering A. Objectivity and the Mangle of Practice. In: Megill A. (ed.) Rethinking Objectivity. Durham: Duke University Press, 1994. Pp. 109-125.

31. Gastev A.K. New cultural attitude. "Orga-biblioteka CIT", 1924, No. 3, ed. 2nd. Moscow: VTSSPS-CIT. URL: http://ruslit.traumlibrary.net/book/gastev-kak-nado-rabotat/gastev-kak-nado-rabotat.html\#return_n_6 (date accessed: 01/22/2020).

32. Gastev A.K. How to work. Arkhangelsk: Publishing House of the Arkhangelsk Provincial Soviet Party School named after Lenin, 1922.

33. Platonov A.P. Juvenile sea. In: Foundation pit. Juvenile sea. Stories. Moscow: Fiction, 1977. Pp. 116-191.

34. Krakauer Z. Mass ornament. Weimar Essays. Per. with him. ed. N. Fedorova. Moscow: Ad Marginem Press, 2019.

35. Werrett S. "Peasants are NOT working”. M. Phil, History of Science, University of Cambridge, 1996, unpublished ms.

36. Foucault M. Words and Things. Archeology of the Humanities. Translation from French by V.P. Vizgin and N.S. Avtonomova. St. Petersburg: A-cad, 1994;

37. Sirotkina I.E. Is the Central Labor Institute the embodiment of utopia? Questions of the history of natural science and technology. 1991, no. 2, pp. 67-72.

38. Adonyeva S.B., Veselova I.S., Marinicheva Yu.Yu., Petrova L.F. Primary Signs. Assigned Reality. St. Petersburg: Propp Center, 2017.

39. Butler J. Gender Trouble: Feminism and the Subversion of Identity. New York, 1990.

40. Noland C. Agency and Embodiment: Performing Gestures. Producing Culture. Cambridge, MA: Harvard University Press, 2009.

41. Merleau-Ponty M. Phenomenology of Perception. Trans. by D.A. Landes. New York: Routledge, 2012.

42. Sheets-Johnstone M. The Primacy of Movement. Exp. $2^{\text {nd }}$ ed. Amsterdam: John Benjamins, 2011.

43. Sirotkina I.E. The sixth sense of the avant-garde: dance, movement, and kinaesthesia in the lives of poets and artists. 2nd ed. St. Petersburg: Publishing house of the European University, 2016.

Irina E. Sirotkina, Institute for the History of Natural Science and Technology Russian Academy of Science, Russian Federation.

E-mail: isiro1@yandex.ru 